\title{
Modeling the Association between Deliberative Beliefs and Organizational Citizenship Behavior among Teachers
}

\author{
Chun-wen $\operatorname{Lin}^{1}$ \\ ${ }^{1}$ Department of Child Care, National Pingtung University of Science \& Technology, Pingtung, Taiwan \\ Correspondence: Chun-wen Lin, Department of Child Care, National Pingtung University of Science \& \\ Technology, No. 1 Shue-fu road, Neipu, Pingtung 91201, Taiwan. Tel: 886-8-770-3202. E-mail: \\ cwlin@mail.npust.edu.tw
}
Received: November 11, 2016
Accepted: December 12, 2016
Online Published: April 29, 2017
doi:10.5539/ies.v10n5p188
URL: https://doi.org/10.5539/ies.v10n5p188

\begin{abstract}
Aristotle proposed that deliberation in the political arena facilitates citizens' abilities to deliberate about the ultimate interests of human beings, identify the highest human benefit achievable given the circumstances, and develop moral virtues and good deeds. Appealing to Aristotelian deliberation, this study investigates the relationships among normative deliberative beliefs, personal deliberative beliefs, and organizational citizenship behavior among senior/vocational high school teachers. A survey was completed by 202 Taiwanese senior/vocational high school teachers. The results, derived from structural equation modeling, reveal that the direct contribution of normative deliberative beliefs to organizational citizenship behavior was rather weak, but personal deliberative beliefs contribute significantly to the organizational citizenship behavior in teachers. Implications for these findings are discussed.
\end{abstract}

Keywords: deliberative belief, organizational citizenship behavior, senior/vocational high school teachers, structural equation modeling

\section{Introduction}

Organizational citizenship behavior is important for the overall improvement, effectiveness, and development of school institutions and plays an important role in ensuring school effectiveness. Teachers who develop appropriate organizational citizenship behaviors may demonstrate the patterns of altruism, courtesy, conscientiousness, sportsmanship and civic virtue, all of which support the social and psychological functioning and effectiveness of a school. Given the trend toward school effectiveness, there is a need to examine the factors that augment teachers' organizational citizenship behaviors.

In most research studies, organizational citizenship behavior has been studied as an outcome variable with organizational commitment, job satisfaction, and organizational justice as independent variables. Cinar et al. (2013) found that organizational silence had a significant negative influence on organizational citizenship behavior. However, the relationship between deliberation and civic engagement has been examined in only a few studies (Borgida, Worth, Lippmann, Ergun, \& Farr, 2008).

Recently, democratic theorists have argued that political processes require adequate public deliberation to be considered legitimate. These arguments reinforce the supposition that deliberation enhances democracy, increases autonomy and strengthens one's feeling of belonging to a community (Chambers, 1996; Barber, 1984). Gutmann and Thompson (1996) reconstruct our political theory so that the theory promotes a more deliberative citizenry. However, deliberation is not without its critics (Sanders, 1997; Young, 1996). Young (1996) critiques democratic deliberation because long-lasting splinter groups lack the resources to engage in deliberation effectively and thereby perpetuate their dissatisfaction in reaching consensus. Moreover, the government needs public deliberation to legitimate political policies and their implementation (Longstaff, Secko, Capurro, Hanney, $\&$ McIntyre, 2015). Therefore, the relationship between deliberation and organizational citizenship behavior is in need of investigation. To understand how high school teachers' deliberative beliefs influence their organizational citizenship behaviors, we used structural equation modeling to test our hypotheses.

In the present study, organizational citizenship behavior is explored as an outcome variable of deliberative beliefs as an indicator of organizational citizenship behavior as is suggested by Aristotelian deliberation theory. 


\section{Theoretical Frameworks}

This study investigates the relationship between teachers' deliberative beliefs and teachers' organizational citizenship behaviors. As human character has not altered much since Aristotle's time, his discussion in Nicomachean Ethics still seems appropriate to contemporary discussions of human nature. Aristotle emphasized that "it is not easy to be good" and argued that knowledge and intelligence are not ends in themselves - but means to our ends (Aristotle, 1947). Investigation and deliberation followed by decision are required for one to act morally. Aristotle required practical deliberation, which takes into account the context of one's situation, to determine the appropriate practical action. The framework of our study is based on Aristotelian virtue ethics, which focuses on the necessity of deliberation for moral action and for pursuing human goods.

Aristotle recognized that virtuous character is not sufficient for goodness. Instead, practical wisdom is fundamental and requires deliberation on one's habituated inclinations to refine their goodness. Aristotle wrote, "we cannot be fully good without intelligence" and "full virtue cannot be acquired without intelligence." That is, although intelligence is essential for full virtue, intelligence must be nourished though means of practical deliberation in particular situations to acquire practical wisdom to achieve one's end-virtuous action (Aristotle, 1947). Aristotle argued that moral deliberation seeks reasons, which may lead us to repudiate counterfeit moral beliefs and discover authentic goodness. Given this theory, our aim is to further substantiate Aristotle's theory by modeling the relationship between deliberation and organizational citizenship behavior through structural equation modeling of a data set sampling Taiwanese senior high and vocational high school teachers.

\subsection{Deliberative Beliefs}

Deliberation, which has roots in democracy and natural human capacities, considers different opinions and interests to reach commonalities or consensus by collective reasoning for the public good. Deliberative processes must provide participants with balanced information, ensure minority views are considered, and create opportunities for open deliberation and examination of competing claims (Chambers, 1996).

The belief in these capacities of deliberation is defined as deliberative belief (Sass \& Dryzek, 2014). As Borgida and Worth (2008) note, "Personal deliberative beliefs, 'walk the walk' - supporting personal beliefs are quite peculiar from normative deliberative beliefs which simply 'talk the talk' by recognizing that there is some benefit to the normative belief items" (Borgida et al., 2008). Deliberative beliefs were measured using two subscales, derived from Borgida and Worth (2008), representing normative and personal deliberative beliefs. For each group, participants responded to questions about their knowledge of normative deliberative beliefs, such as "Everyone should have an equal say when making important decisions that affect everyone," and responses were rated on a 5-point Likert-type scale (strongly disagree to strongly agree). To assess personal deliberative beliefs, participants were asked to indicate how often they believed these statements characterized recent disputes on political subjects within their communities. Participants' responses to questions about personal deliberative beliefs used a 10-point Likert-type scale. The 7-item scale in the Borgida et al. (2008) scale was reliable (Cronbach $\alpha=.75$ ). Items included, "I participate in discussions with people who have very different views from my own."

\subsection{Organizational Citizenship Behavior}

OCB is defined as employee behavior that is discretionary and not formally rewarded and that supports the social and psychological functioning and effectiveness of an organization (Organ, 1997). Organ (1988) first adduced a five-factor model of OCB comprised of altruism (helping others), courtesy (polite and respectful behaviors), conscientiousness (acceptance of and compliance with policies), civic virtue (taking on extra responsibilities and being involved in the professional life of an organization), and sportsmanship (tolerating inconveniences and impositions). Teacher OCBs, although seldom researched, have an important role to play in the successful functioning of educational institutions because teachers' successful completion of their duties and tasks is necessary but not sufficient for teacher effectiveness. Duties for teachers are often fixed as following set curriculum and preserving professional autonomy within their organizations and with other school stakeholders (e.g., principals, colleagues, parents, and students).

Organizational citizenship behaviors are influenced by interpersonal justice rather than distributive justice and procedural justice (Rego \& Cunha, 2010). Lim and Loosemore (2017) found that interpersonal justice is a key ingredient in securing positive organizational citizenship behaviors in construction projects. Chan and Lai (2017) found that communication satisfaction influenced organizational citizenship behavior.

The aim of this study is to explain a causal relationship between deliberative beliefs and OCB. The hypotheses of this study are as follows: 
Hypothesis 1: Normative deliberative beliefs are a predictor of organizational citizenship behavior in teachers.

Hypothesis 2: Personal deliberative beliefs are a predictor of organizational citizenship behavior in teachers.

\section{Method}

\subsection{Participants}

Two hundred and six senior high and vocational school teachers were recruited from 15 senior/vocational high schools in Taiwan. Of these participants $35.1 \%$ were private school teachers and $39.6 \%$ were vocational school teachers; $40.1 \%$ were male, $59.9 \%$ were female.

\subsection{Measure}

The measures utilized in this study were selected to facilitate the assessment of the reliability and validity of teachers' personal deliberative belief scale (TPDBS), and teachers' normative deliberative belief scale (TNDBS), and organizational citizenship behavior scale. For the purposes of this research, the TPDBS and TNDBS were used in assessment of the psychometric properties of teachers' deliberative beliefs. We assessed teachers' deliberative beliefs by the Deliberative Beliefs Scale (Borgida et al., 2008). The DBS consists of 8 items divided into 2 subscales measuring personal and normative aspects of deliberative beliefs. Each DBS subscale consists of 4 items on a 10-point Likert-type scale, where $1=$ None of the time, $5=$ About half of the time, and $10=$ All of the time.

We assessed teachers' organizational citizenship behavior by the OCB Scale (Somech \& Ron, 2007) based on the OCB Scale of Podsakoff et al. (1990), which had been specifically adjusted to suit educational contexts. The OCB consists of 24 items divided into 5 subscales measuring altruism, courtesy, conscientiousness, civic virtue, and sportsmanship. Altruism, which represents teachers' discretionary behaviors that influence helping other teachers with organizationally relevant work, was measured with five items (e.g., "This teacher helps others who have been absent"). Conscientiousness, which reflects teachers' discretionary behaviors that go beyond the minimum role requirements of the school, such as taking breaks, obeying rules, daily attendance, was measured with five items (e.g., "Attendance at work is above the norm"). Sportsmanship, which refers to teachers' willingness to tolerate less than ideal environments without complaint, was measured by five items (e.g., "Always finds fault with what the organization is doing" (reversed item)). Courtesy, which reflects teachers' discretionary behavior aimed at preventing job-related issues with others, was measured by four items (e.g., "Tries to avoid creating problems for colleagues"). Civic virtue, which refers to behaviors that represent a teacher's participation in or concerned about the life of the school, was measured by five items (e.g., "Attends meetings that are not mandatory but are considered important."). Items were measured on a 7-point Likert-type scale ranging from $1=$ strongly agree to $7=$ strongly disagree. The items of each scale were summed and higher values represent higher levels of each type of OCB.

\subsection{Data Analysis}

Data were analyzed through investigations of ANOVA and Pearson correlations using SPSS version 17.0. Then, the AMOS software package (version 17.0) was used to examine the hypothetical causal model containing both manifest and latent variables.

\section{Results}

\subsection{Scaling Qualities}

In the teacher sample, higher mean scores were found for the normative deliberative belief scale than for the personal deliberative belief scale. Scores ranged from 1 to 5 on the normative deliberative belief and OCB scales but ranged from 1 to 10 on personal deliberative belief scale according to original scale developed by Borgida et al. (2008). In relation to floor effects, for all four items of the TNDBS only $0.5 \% \sim 1.0 \%$ of respondents selected the lowest response category, for all four items of the TPDBS only $0 \sim 0.5 \%$ of respondents selected the lowest response category, and for all 24 items of the TOCBS only $0.5 \% \sim 8.4 \%$ of respondents selected the lowest response category. In relation to ceiling effects, for all four items of the TNDBS between $45.5 \% \sim 50 \%$ of respondents selected the highest response category, for all four items of the TPDBS $8.9 \% \sim 16.8 \%$ of respondents selected the highest response category, and for all 24 items of the TOCBS $8.4 \% \sim 34.0 \%$ of respondents selected the highest response category. The mean, standard deviation, skewness, kurtosis, and internal consistency is shown in Table 1. 
Table 1. Mean, S.D., skewness, kurtosis, internal consistency for TNDBS, TPDBS, TOCB scales

\begin{tabular}{|c|c|c|c|c|c|}
\hline Facets (number of items) & mean & standard deviation S.D. & skewness & kurtosis & $\begin{array}{c}\text { internal consistency } \\
\text { Cronbach's alpha }\end{array}$ \\
\hline $\begin{array}{l}\text { NDB1 } \\
\text { Likert } 5\end{array}$ & 4.33 & .72 & -1.08 & 1.82 & \\
\hline NDB2 & 4.33 & .74 & -1.27 & 2.90 & \\
\hline NDB3 & 4.37 & .69 & -1.18 & 2.54 & \\
\hline NDB4 & 4.41 & .69 & -1.30 & 2.96 & \\
\hline $\begin{array}{c}\text { PDB1 } \\
\text { Likert10 }\end{array}$ & 7.17 & 1.64 & -1.40 & .42 & \\
\hline PDB2 & 7.43 & 1.55 & -.53 & .30 & \\
\hline PDB3 & 7.85 & 1.73 & -.72 & .15 & \\
\hline PDB4 & 7.86 & 1.60 & -.65 & .31 & \\
\hline NBD total (4) & 4.36 & .62 & -1.36 & 4.40 & .90 \\
\hline PBD total (4) & 7.58 & 1.36 & -.69 & 1.05 & .89 \\
\hline $\begin{array}{c}\text { Alt } \\
\text { Likert } 7\end{array}$ & 5.78 & .82 & -.96 & 2.17 & .93 \\
\hline Con & 5.62 & .80 & -.58 & .27 & .88 \\
\hline Spo & 5.32 & 1.09 & -.63 & .54 & .89 \\
\hline $\mathrm{Cou}$ & 5.63 & .94 & -1.02 & 2.38 & .91 \\
\hline Civ & 5.52 & .87 & -.49 & .25 & .86 \\
\hline OCB total (5) & 5.60 & .69 & -.31 & -.31 & .81 \\
\hline
\end{tabular}

Note. NBD: normative deliberative belief, PBD: personal deliberative belief, Alt: altruism, Con: conscientiousness, Spo: sportsmanship, Cou: courtesy, Civ: civic virtue

\subsection{Correlation Analyses}

To elucidate the relationships between personal deliberative beliefs, normative deliberative beliefs, and organizational citizenship behavior in teachers, the correlation of each individual's personal and deliberative beliefs was tested. Table 2 illustrates that teachers' personal deliberative beliefs were related to their organizational citizenship significantly. For example, the coefficients of the correlations between personal deliberative belief, normative deliberative belief, and organizational citizenship behavior were $0.38(p<0.01)$ and $0.27(p<0.01)$, respectively. The results indicate that, for these high school teachers, those possessing stronger personal or normative deliberative beliefs were inclined to perform organizational citizenship behaviors. There is a stronger relationship between personal deliberative belief and OCB than between normative deliberative belief and OCB.

Table 2. Correlations between normative, personal deliberative belief, and OCB

\begin{tabular}{llllllll}
\hline & NBD & PBD & Alt & Con & Spo & Cou & Civ \\
\hline NBD & 1 & & & & & & \\
PBD & $.53^{* *}$ & 1 & & & & & \\
Alt & $.34^{* *}$ & $.37^{* *}$ & 1 & & & & \\
Con & $.17^{*}$ & $.28^{* *}$ & $.61^{* *}$ & 1 & & & \\
Spo & $.19^{* *}$ & $.31^{* *}$ & $.44^{* *}$ & $.39^{* *}$ & 1 & & \\
Cou & $.16^{*}$ & $.17^{*}$ & $.40^{* *}$ & $.51^{* *}$ & $.39^{* *}$ & 1 & \\
Civ & $.20^{* *}$ & $.33^{* *}$ & $.64^{* *}$ & $.67^{* *}$ & $.36^{* *}$ & $.52^{* *}$ & 1 \\
\hline
\end{tabular}

$* \mathrm{p}<0.05, * * \mathrm{p}<0.05$.

Note. NBD: normative deliberative belief, PBD: personal deliberative belief, Alt: altruism, Con: conscientiousness, Spo: sportsmanship, Cou: courtesy, Civ: civic virtue

\subsection{Preliminary Model Fit Criteria}

This research used structural equation modeling to evaluate the relation between deliberative beliefs and OCB. The evaluation criteria of model fit adopted by Bagozzi and Yi (1988) consists in the preliminary fit criteria, 
overall model fit of the structural model, and fit of the internal structural model (measurement model).

None of the error variance was negative. Skewness and kurtosis of the observation variable did not exceeding 3 and 7, respectively, as shown in Table 1. Standardized error variance was between .02 and .28 and reached a 0.05 significance level. The factor loading of each observation variable was significant between .51 and .87 and was over the 0.50 evaluation level. Thus, the model of factors met the preliminary fit criteria for SEM analysis (Hair et al., 2006).

\subsection{Measurement Model}

The overall fit of the measurement model was acceptable. The validity and reliability of the instruments (i.e., Teacher Normative Deliberative Beliefs Scale, Teacher Personal Deliberative Beliefs Scale) in the pilot study were examined with exploratory factor analysis (EFA) and Cronbach's alpha. The variance extracted for each constructs (TNDBS and TPDBS) were $76 \%$ and $70 \%$, respectively, with factor loadings ranging from .84 to .90 . Moreover, Cronbach's alpha values were .90 and .86 , respectively. Therefore, in terms of validity and reliability of TNDBS and TPDBS, the results were deemed satisfactory.

SEM was conducted to test the validity of the Teacher Organizational Citizenship Behavior Scale (TOCBS). A maximum likelihood estimation was utilized. We also employed bootstrapping to enhance the quality of the models. An $\mathrm{X}_{2} / \mathrm{df}$ less than 3.0, the Tucker-Lewis index (TLI), comparative fit index (CFI) values of greater than .90 , and root mean square error of approximation (RMSEA) values of less than .08 reflect an acceptable fit. As a result, TLI and CFI values were .90 and .92, respectively, and RMSEA and SRMR values were 0.09 and 0.06 , respectively. All indexes but CFI suggested the TOCBS model had an acceptable fit and, thus, the validity and reliability of TOCBS were deemed satisfactory.

Convergent validity should be achieved in order to fulfill construct validity. Standardized loading estimates ranged from .54 to .87 , which indicated satisfactory convergent validity, and of all the subscales only the loading estimate of sportsmanship and courtesy were lower than 0.7 . Overall, the measurement model was valid and reliable.

According to the Table 3, the composite reliabilities of the three latent variables (TNDBS, TPDBS, TOCB) were $.89, .86$ and .79 , respectively, and each exceeded the critical value of 0.6 . Moreover, the average variance extracted from the latent variables of TNDBS and TPBDS were .68, and .61, respectively, and both exceeded the critical value of 0.5 . The exception was the OCB variable, which was only 0.48 .

Table 3. Composite reliability and average variance extracted from latent variable

\begin{tabular}{lcc}
\hline & Composite reliability & Average variance extracted \\
\hline NDB & .89 & .68 \\
PDB & .86 & .61 \\
OCD & .79 & .48 \\
\hline
\end{tabular}

\subsection{Deliberation-OCB Overall Model Fit}

Figure 1 illustrates the causal relationships between teacher's deliberative beliefs and teachers' OCBs. Fit statistics indicated that the model provided an acceptable fit to the sample data $\left(\mathrm{X}^{2} / \mathrm{df}=2.42, \mathrm{GFI}=.90, \mathrm{TLI}=.92\right.$, $\mathrm{CFI}=.93, \mathrm{RMSEA}=.08, \mathrm{SRMR}=0.06)$ as shown in Table 4 (Kline, 2005). This model shows that teachers' personal deliberative beliefs impacted their organizational citizenship behavior $(\gamma=.39, p<.001)$, but teachers' normative deliberative beliefs did not impact their organizational citizenship behavior significantly. As a result, teacher's personal deliberative beliefs served as an independent variable for the impact of OCB in senior/vocational high school teachers. In total $18 \%$ of the variance in the teachers' OCB was accounted for by their personal deliberative beliefs. 
Table 4. Model evaluation measures of the overall model fit $(n=206)$

\begin{tabular}{|c|c|c|}
\hline Evaluation items & Analyses results & Evaluation results \\
\hline Did $\mathrm{x} 2$ reach significance $\mathrm{p}>.05$ & $\mathrm{p}=0.00$ & Not satisfactory \\
\hline $\operatorname{Did} \chi^{2} / \mathrm{df}<3$ & $\begin{array}{l}\mathrm{CMIN} / \mathrm{DF}=154.27 / 62 \\
2.42\end{array}$ & Yes \\
\hline Did GFI $>0.9$ & 0.9 & Yes \\
\hline Did TLI(NNFI) $>0.9$ & 0.92 & Yes \\
\hline Did CFI $>0.9$ & 0.93 & Yes \\
\hline Did INI $>0.9$ & 0.93 & Yes \\
\hline Did NFI $>0.9$ & 0.90 & Yes \\
\hline Did RMSEA $>0.8$ & 0.08 & Yes \\
\hline Did PNFI $>0.5$ & 0.71 & Yes \\
\hline Did PCFI $>0.8$ & 0.74 & Yes \\
\hline Did SRMR $<0.6$ & 0.06 & Yes \\
\hline
\end{tabular}

\subsection{Testing of the Hypotheses}

The results demonstrated that teachers' personal deliberative beliefs (PDB) positively predicted teachers' organizational citizenship behavior (OCB). However, teachers' normative deliberative beliefs (NDB) did not predict teachers' organizational citizenship behavior $(\mathrm{OCB})$ significantly. The structural equation modeling produced the following path coefficients: $\mathrm{PDB}=>\mathrm{OCB}=.39, \mathrm{t}=3.59, \mathrm{p}<.001 ; \mathrm{NDB}=>\mathrm{OCB}=0.07, \mathrm{t}=0.64, \mathrm{p}=.52$; where $\mathrm{PDB}=>\mathrm{OCB}$ represents the path coefficient between $\mathrm{PDB}$ and $\mathrm{OCB}$ and $\mathrm{NDB}=>\mathrm{OCB}=0.07$ represents the path coefficient between NDB and OCB. The correlation between NDB and PDB is significant. The data analysis supported Hypothesis 2, indicating that the correlation between personal deliberative beliefs and organizational citizenship behavior was significant.

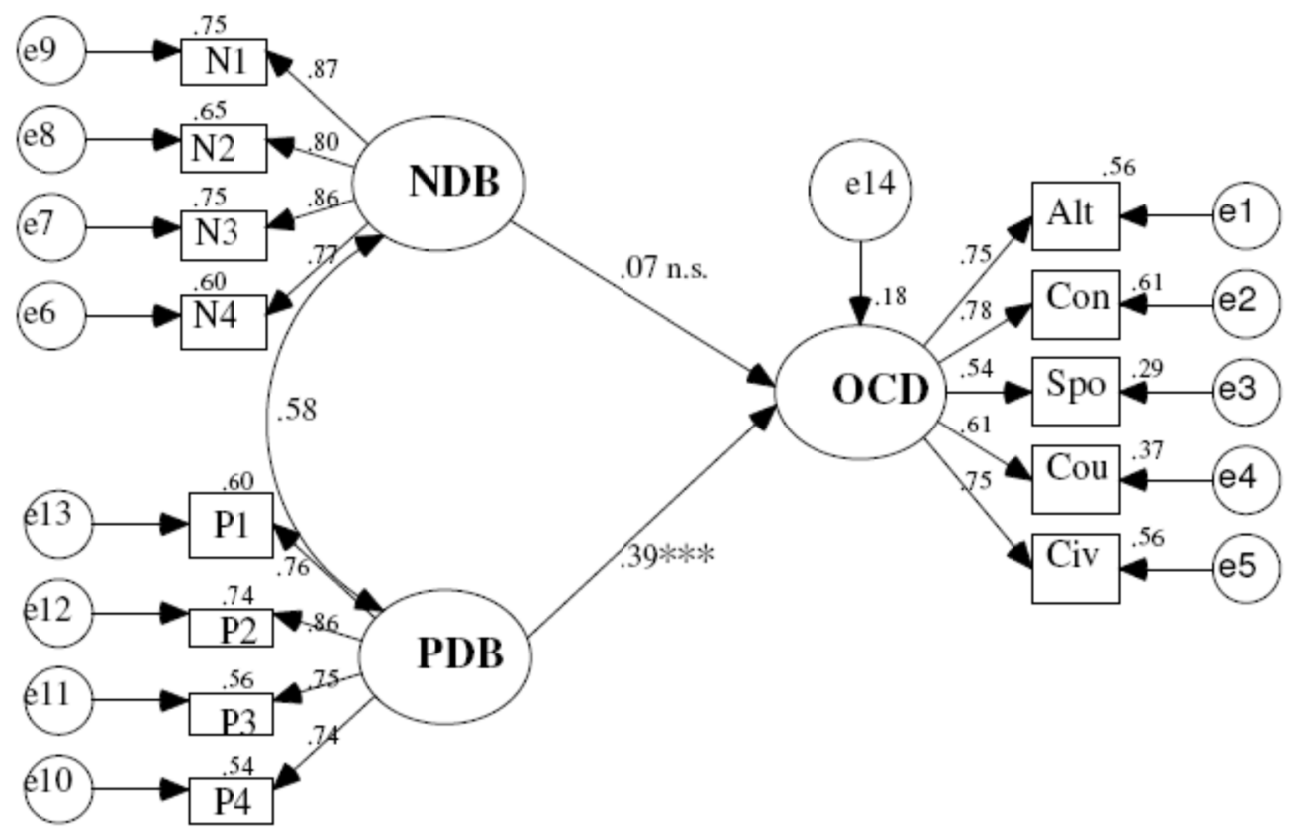

Figure 1. Results of theoretical model analysis (standard solution), NDB = Normative Deliberative Belief, PDB= Personal Deliberative Behavior, $\mathrm{OCD}=$ Organizational Deliberative Behavior, Alt= Altruism.

Con $=$ Conscientiousness, $\mathrm{Spo}=$ Sportsmanship. $\mathrm{Cou}=$ Courtesy, $\mathrm{Civ}=$ Civic Virtue. $* * *=$ regression weight is significantly different from zero at the .001 level 


\section{Discussions}

People often do not deliberate before making decisions and instead act intuitively (Kahneman, 2011). However, what would happen if people took time to deliberate before acting? The results of this research reveal that people with personal deliberative beliefs will tend toward organizational citizenship behavior. Mutz (2006) has argued that personal deliberation is the precursor to public deliberation, and this study also points to personal deliberation as a precursor to organizational citizenship behavior.

For democratic societies to thrive, citizens should be prepared to be democratic and engage organizational citizenship behavior in diverse and pluralistic circumstances (Bohman, 1996; Fishkin, 1991). Deliberative democratic theories propose models of participation committed to the public deliberative processes that are necessary for the legitimacy of collective decision-making in a pluralistic public sphere that deals with conflicts about the common good. Legitimacy is established through dialogue; however, not just any sort of dialogue can achieve this end. Habermas $(1984,1990)$ argued that dialogue should build in an "ideal speech situation" and members of the public sphere ought to adhere to certain rules to ensure such situations occur. The rules are as follows: "1. every subject with the capability to speak and act is allowed to take part in a discussion. 2a. everyone is allowed to reason any assertion whatever. $2 b$. everyone is allowed to advise any assertion whatever into the discourse. 2c. Everyone is allowed to express their desires, attitudes and needs without any hesitation. 3. No speaker may be prevented, by internal or external pressure, from exercising his rights as laid down in (1) and (2)". Some of the contents of our deliberative belief scale are derived from Habermas's "ideal speech situation". The results of our empirical investigation revealed that personal deliberative beliefs, which represent the ideal speech situation, are associated with organizational citizenship behavior.

Kymlicka (1995) notices that there is a debate over whether, in civic education, the fundamental value within liberal theory is autonomy or tolerance. Galston (1995) proposes that tolerance is essential for civic education in schools and that the cultivation of tolerance requires a minimal awareness of different ways of life. On the other hand, Gutmann (1995) claims that teaching skills and virtues of democratic citizenship involves individuality and autonomy. The core of our study is deliberative belief, which includes toleration of opposing opinions, autonomous expression of others' positions, and others' competencies of speaking and acting in the deliberative meeting.

In integrating the findings of this study into the existing literature, we found that the negative correlation of organization silence and OCB (Cinar et al., 2013) indicated that deliberation, rather than silence, ought to have a positive influence on OCB.

We recommend further qualitative and quantitative research to explore the factors contributing to organizational citizenship behavior, particularly its relationships with organizational deliberation, organizational democracy, and organizational justice in larger samples and in countries other than Taiwan. Moreover, further research to develop an Asian norm for the model is required.

This study included only a few variables in exploring the relationship between deliberative beliefs and OCB. Indeed, there are many factors, such as organizational justice, organizational commitment, and organization atmosphere that might affect the model. Furthermore, sampling only teachers might limit the strength of the results.

Further studies using more variables or different occupations should be considered for assessing the relationship between deliberative beliefs and organizational citizenship behavior.

\section{Conclusions}

In this study, teachers with stronger personal deliberative beliefs displayed higher achievement in OCB. Aristotle argues that good deliberation (euboulia) will reach the right conclusion when one is given an appropriate amount of time to reason through valid practical syllogisms. The findings of our research corroborate well with Aristotle's theory. That stronger levels of personal deliberative beliefs affect teachers' OCB positively supports Aristotle's thought that the inclusion of deliberation, which is necessary for reflecting on all the aspects of a situation, leads to actions that accord with virtue (Aristotle, 1947).

There are inconsistencies between one's knowledge and actual conduct, which reinforce the idea that Aristotelian deliberation is not simply a matter of knowledge, character, or mere logical determination but requires a passionate element. In his words, "ethos, pathos, and logos" are the requirements of deliberation that lead to virtuous action.

According to Aristotle, we should expect that teachers' moral excellence and virtuous action in school contexts $(\mathrm{OCB})$ are based on habit and not on teaching. Habit requires deliberative processes that nourish practical 
wisdom (phronesis) by reflecting on and changing one's unhelpful patterns of behavior and thus overcome human weakness (akrasia). Therefore, it is recommended that deliberative pedagogy, deliberative leadership, and deliberative governance should be performed in authentic circumstances to strengthen teachers' personal deliberative beliefs and, thereby, develop teachers' sunesis (the capacity of judging well) to attain OCB and pursue institutional goods. Deliberative bodies in educational institutions should also be established to fulfill the needs of authentic deliberation. In other words, since personal deliberative beliefs increased proportionally to teachers' OCB, it is recommended that educational institutions encourage practical deliberation in special situations and particular cases, rather than merely reinforcing normative deliberative knowledge, so that teachers can engage in meaningful deliberation with "right beliefs".

\section{Acknowledgments}

We would like to thank the participants at the schools sampled for data collection in this research.

\section{References}

Aristotle. (1947). Nichomachean Ethics (trans. H. Rackham). Cambridge: Harvard University Press.

Bagozzi, R. P., \& Yi, Y. (1988). On the Evaluation of Structural Equation Models. Journal of the Academy of Marketing Science, 16, 74-94.

Barber, B. (1984). Strong democracy: Participatory politics for a new age. Berkeley, CA: University of California Press.

Bohman, J. (1996). Public deliberation: Pluralism, complexity, and democracy. Cambridge, MA: MIT Press.

Borgida, E., Worth, K. A., Lippmann, B., Ergun, D., \& Farr, J. (2008). Beliefs about Deliberation: Personal and Normative Dimensions. Journal of Social Issues, 64(3), 551-569. https://doi.org/10.1111/j.1540-4560.2008.00577.x

Chambers, S. (1996). Reasonable democracy: Jurgen Habermas and the politics of discourse. Ithaca, NY: Cornell University Press.

Chan, S. H. J., \& Lai, H. Y. I. (2017). Understanding the link between communication satisfaction, percieved justice and organizational citizenship behavior. Journal of Business Research, 70, 214-223. https://doi.org/10.1016/j.jbusres.2016.08.017

Cinar, O., Karcioglu, F., \& Aliogullari, Z. D. (2013). The relationship between organizational silence and organizational citizenship behavior: A survey study in the province of Erzurum, Turkey. Procedia - Social and Behavioral Sciences, 99, 314-321. https://doi.org/10.1016/j.sbspro.2013.10.499

Fishkin, J. (1991). Democracy and deliberation: New directions for democratic reform. New Haven, CT: Yale University Press.

Gastil, J., \& Dillard, J. (1999). Increasing political sophistication through public deliberation. Political Communication, 16, 3-23. https://doi.org/10.1080/105846099198749

Gutmann, A., \& Thompson, D. (1996). Democracy and disagreement. Cambridge, MA: Belknap.

Habermas, J. (1984). The theory of communicative action, vol. I: Reason and the rationalization of society (T. McCarthy, trans.). Boston: Beacon.

Habermas, J. (1990). Discourse ethics: Notes on a program of philosophical justification. Moral Consciousness and Communicative Action. Trans. C. Lenhart and, S.W. Nicholson. Cambridge: MIT Press.

Hair, J. F., Black, W. C., \& Babin, B. J. (2006). Multivariate data analysis (6th ed.). New York: Macmillian.

Kahneman, D. (2011). Thinking fast and slow. New York: Macmillan.

Kline, R. B. (2005). Principles and practice of structural equation modeling (2nd ed.). New York: Guilford Press.

Lim, B. T. H., \& Loosemore, M. (2017). The effect of inter-organizational justice perceptions on organizational citizenship behaviors in construction projects. International Journal of Project Management, 35, 95-106. https://doi.org/10.1016/j.ijproman.2016.10.016

Longstaff, H., Secko, D. M., Capurro, G., Hanney, P., \& McIntyre, T. (2015). Fostering citizenship deliberation on the social acceptability of renewable fuels policy: The case of advanced lignocellulosic biofuels in Canada. Biomass and Bioenergy, 74, 103-112. https://doi.org/10.1016/j.biombioe.2015.01.003

Mutz, D. C. (2006). Hearning the other side: Deliberative vs. participatory democracy. New York, NY: 
Cambridge University Press. https://doi.org/10.1017/CBO9780511617201

Organ, D. W. (1997). Organizational citizenship behavior: It's construct cleanup time. Human Performance, 10, 85-97. https://doi.org/10.1207/s15327043hup1002_2

Rego, A., \& Cunha, M. P. (2010). Organizational justice and citizenship behaviors: A study in the Portuguese cultural context. Applied Psychology, 59(3), 404-403. https://doi.org/10.1111/j.1464-0597.2009.00405.x

Sanders, L. (1997). Against deliberation. Political Theory, 25, 347-376. https://doi.org/10.1177/0090591797025003002

Sass, J., \& Dryzek, J. S. (2014). Deliberative culture. Political Theory, 42(1), 3-25. https://doi.org/10.1177/0090591713507933

Somech, A., \& Ron, I. (2007). Promoting organizational citizenship behavior in schools: The impact of individual and organizational characteristics. Educational Administration Quarterly, 43(1), 38-66. https://doi.org/10.1177/0013161X06291254

Young, I. (1996). Communication and the other: Beyond deliberative democracy. In S. Benhabib (Ed.), Democracy and difference: Contesting the boundaries of the political (pp. 120-135). Princeton, NJ: Princeton University Press.

\section{Copyrights}

Copyright for this article is retained by the author(s), with first publication rights granted to the journal.

This is an open-access article distributed under the terms and conditions of the Creative Commons Attribution license (http://creativecommons.org/licenses/by/4.0/). 